\title{
O BACHAREL E A DOCÊNCIA: AS INFLUÊNCIAS DA PÓS-GRADUAÇÃO NA CARREIRA PROFISSIONAL
}

\author{
V.S. O. Nascimento \\ Instituto Federal do Rio Grande do Norte - Campus Natal Central \\ viviane.nascimento@ifrn.edu.br
}

Submetido 03/03/2017 - Aceito 30/04/2017

DOI: $10.15628 /$ holos.2017.5738

\section{RESUMO}

Temos o objetivo de discorrer sobre os caminhos percorridos por bacharéis à docência no Ensino Superior, em especial, sobre como a pós-graduação influenciou nas trajetórias que os conduziram à docência, considerando que, nesse percurso, imagens e experiências sobre ser professor se constroem e contribuem para suas ações como docentes. Questionamos o que tem conduzido um profissional com formação em curso de bacharelado a exercer a profissão docente. Realizamos uma pesquisa qualitativa com base na metodologia da Entrevista Compreensiva com treze professores com formação em bacharelado que atuam como docentes no Ensino superior da Universidade Federal do Rio Grande do Norte. A Entrevista Compreensiva foi a metodologia eleita por considerá-la capaz de possibilitar a compreensão da multiplicidade de sentidos que conduziram os bacharéis a atuarem como docentes, assim como auxiliará o entendimento sobre às relações entre a sua formação como Bacharel e o exercício da docência universitária. Por meio das análises das falas dos entrevistados, pode ser percebido que os professores relatam sobre a importância da Pós-graduação para a docência universitária, considerando-a como caminho que conduz o bacharel a profissão docente, embora haja a necessidade da ampliação da discussão sobre o atual perfil formativo dos programas de Pós-graduação no Brasil.

PALAVRAS-CHAVE: Formação docente, Ensino Superior, Bacharel docente.

\section{BACHELOR AND TEACHING: THE INFLUENCES OF POSTGRADUATE PROFESSIONAL CAREER}

\begin{abstract}
We have the objective of discussing the paths taken by bachelors to teaching in Higher Education, in particular, about how the graduate influenced the trajectories that led them to teaching, considering that, in this course, images and experiences about being a teacher are built and Contribute to their actions as teachers. We question what has led a professional with training in baccalaureate to practice the teaching profession. We conducted a qualitative research based on the methodology of the Comprehensive Interview with thirteen teachers with a baccalaureate degree who work as teachers in Higher Education at the Federal University of Rio Grande do Norte. The Comprehensive Interview
\end{abstract}

was the methodology chosen to consider it capable of understanding the multiplicity of meanings that led the bachelors to act as teachers, as well as help understand the relationship between their training as a Bachelor and the exercise of university teaching. Through the analysis of the interviewees' speeches, it can be seen that teachers report on the importance of Postgraduation for university teaching, considering it as the path that leads the bachelor to the teaching profession, although there is a need to broaden the discussion about The current formative profile of graduate programs in Brazil

KEYWORDS: Teacher training, Higher education, Teaching Bachelor. 


\section{INTRODUÇÃO}

Ao discutir sobre a formação de bacharéis para o exercício da profissão docente no Ensino Superior não poderia deixar de questionar: o que conduz um profissional com formação em curso de bacharelado a exercer a profissão docente? Nessa busca partir do pressuposto de que, pela própria natureza da formação dos cursos de bacharelado, os bacharéis que atuam como professores, ao escolherem a área de seus estudos na formação inicial, não tinham interesse inicial pela profissão docente e esta escolha decorreu especialmente por meio dos estudos em cursos de pós-graduação.

Partindo dessa questão, tenho como objetivo discorrer sobre as motivações dos bacharéis no processo de definição profissional, em especial, sobre como a pós-graduação influenciou nas trajetórias que os conduziram à docência universitária, considerando que, nesse percurso, imagens e experiências sobre ser professor se constroem e contribuem para suas ações como docentes.

Este trabalho é parte de um estudo mais amplo, no qual desenvolvi uma pesquisa qualitativa com base na metodologia da Entrevista Compreensiva (KAUFMANN, 1996) com treze professores com formação em bacharelado que atuam como docentes no Ensino superior da Universidade Federal do Rio Grande do Norte, em especial, em cursos de bacharelado do Centro de Ciências Sociais Aplicadas, Natal/Rio Grande do Norte.

Elegi as orientações metodológicas da Entrevista Compreensiva, por considerá-la capaz de possibilitar a compreensão da multiplicidade dos sentidos que os bacharéis atribuem a profissão docente, assim como às relações entre a sua formação como Bacharel e o exercício da docência universitária.

O discurso oral do indivíduo é o elemento principal nessa metodologia, pois tem a condição de proporcionar a interpretação dos sentidos e valores explicitados pelos docentes quanto à sua ação, através da palavra coletada por meio de entrevistas. Esta, como instrumento de pesquisa, foi realizada com treze professores que se apresentam neste texto por meio de nomes fictícios escolhidos pelos próprios professores no momento de gravação das entrevistas.

Partindo dessas considerações, organizamos este texto em duas partes, nas quais apresentamos o que estamos compreendendo como experiências formativas e posteriormente, analisamos as trajetórias dos docentes nos cursos de pós-graduação buscando perceber as influencias desses cursos para a formação do bacharel que atua como professor no ensino superior.

\section{O ENSINO SUPERIOR: CENÁRIOS DA DOCÊNCIA}

Considero o conhecimento dos cenários, das trajetórias e das formas como os bacharéis relatam suas experiências de vida o primeiro passo para entender o que os motivaram a se tornarem professores universitários.

Todavia, ao reconhecer o bacharel docente como pessoa, ressalto a importância da compreensão de que todo indivíduo sempre está em relação com uma rede de interdependências (ELIAS, 1998) que envolvem nossas formas de observar o mundo, os valores e os sentidos que atribuímos a realidade. As interdependências nos conduzem, de um lado, a fazermos escolhas que possam suprir as necessidades de um determinado momento de nossas vidas. Por outro lado, as nossas existências estão atreladas às relações que estabelecemos com o outro e com o mundo. $O$ indivíduo está sempre inserido em um conjunto de relações, por isso nossa existência coexiste "[...] num sistema de relações cujos parâmetros principais são a filiação 
e a aliança [...]", fazendo com que nossa existência esteja sempre na e pela relação com o outro (AUGÉ, 1999, p. 28).

Para que seja possível compreender as influencias da pós-graduação na formação do bacharel para a docência no Ensino Superior reconheço que é necessário conhecer as suas experiências formativas, sabendo que elas fizeram parte de situações históricos-sociais diferenciadas, o que possibilita uma vasta significação das formas como se observam os trajetos rumo à docência universitária.

Assim, as explicações que os bacharéis fazem sobre seus caminhos de vida nas dimensões pessoais, profissionais e coletivas, me conduzem à consideração de que as interpretações atribuídas pelos bacharéis sobre suas vidas só podem ser explicitadas em termos de processo, por serem dinâmicas, complexas e não lineares. Nessas explicações, como afirma Elias (1998, p. 35), não existe indícios absolutos, pois "[...] trata-se de uma circularidade características dos próprios dos acontecimentos."

Afirma Nóvoa (1995, p. 25) que "[...] o homem define-se pelo que consegue fazer com o que os outros fizeram dele." Tal consideração me permite a produção de um conhecimento mais amplo sobre os bacharéis que exercem a docência, pois permite a análise das suas formas de ser e estar na profissão para além das dimensões profissionais e particulares, pois elas estão em relação com outras instâncias: a família, a universidade, os sindicatos, a religião, dentre tantas outras às quais nos filiamos e que contribuem para as formas de ser e agir onde estamos inseridos.

As experiências vividas possibilitam que cada pessoa já chegue à universidade com saberes sobre o que seja ser professor, advindos de suas experiências como alunos, de experiências familiares (quando se convive com familiares ou amigos próximo que são professores), religiosas, de atividades como as "aulas particulares", muitas vezes presentes na vida do jovem, dentre outros diferentes contatos dentro ou fora das instituições de formação acadêmica, que possibilitam que sejam formados alguns saberes sobre a profissão docente.

Trata-se do conjunto de experiências que, como afirma Pimenta (2007)

[...] Ihes possibilita dizer quais foram os bons professores, quais eram bons em conteúdos, e não em didática, isto é, não sabiam ensinar. Quais professores foram significativos em suas vidas, isto é, contribuíram para sua formação humana. Também sabem sobre o ser professor por meio da experiência socialmente acumulada, as mudanças históricas da profissão, o exercício profissional em diferentes escolas, a não valorização social e financeira dos professores [...] sabem um pouco sobre as representações e estereótipos que a sociedade tem dos professores, através dos meios de comunicação (PIMENTA 2007, p. 20).

Assim, as experiências formativas possibilitam a construção de saberes sobre um determinado fenômeno, podendo ainda ser ampliadas nas relações pessoais, com o outro e com o mundo nos contextos em que está inserido, tornando-os mais elaborados e sistematizados. As experiências formativas podem ser entendidas como aquelas que se processam ao longo da vida, da formação humana, como "[...] processo de desenvolvimento e estruturação da pessoa que se realiza com o duplo efeito de uma maturação interna e de possibilidades de aprendizagem, de experiências dos sujeitos" (GARCIA, 1999, p. 19).

Essas experiências, segundo Houssaye (2004), se articulam com continuidades e rupturas, reelaboração do que se conhece, estando abertas às incertezas. Dessa forma, ao conceber a formação como experiência, parto do pressuposto de que a experiência "[...] é englobante, é um processo que envolve todas as dimensões da pessoa (o afetivo, o racional e o corporal, sempre 
estão estreitamente ligados)" (HOUSSAYE, 2004, p. 32). A pessoa em processo de formação, nesse sentido, se apresenta como "maciça", portadora de toda uma experiência vivida relacionada ao seu mundo.

As experiências formativas desse modo se opõem às formações institucionalizadas, considerando que estas tendem a separar a aprendizagem da experiência, pois

[...] faz com que a experiência (estágio prático) seja antecedida por aquilo que se apresenta como um aprendizado, uma preparação (estágio teórico), pronta a querer em seguida retomar a experiência em uma nova aprendizagem (estágio de aperfeiçoamento, aprofundamento e especialização) (HOUSSAYE, 2004, p. 32).

No caso dos entrevistados, suas experiências com a docência surgem no decorrer de suas vidas como alunos, como parentes de professores, por meio das práticas religiosas, que posteriormente se tornam mais sistematizadas nas experiências acadêmicas e profissionais nos diferentes contextos histórico-sociais que cada um deles vivenciam. O conhecimento da docência surge inicialmente com imagens de professores, que se transformam em vivências como professores na medida em que se envolvem com a profissão ainda que de forma "inesperada."

As escolhas que são feitas e os caminhos que trilhamos fazem parte de um movimento complexo, no qual as decisões que tomamos são pautadas pelas redes de interdependências (ELIAS, 1998) em que estamos envolvidos.

Muitas dessas escolhas decorrem do contexto histórico social vivenciado, no qual pode ser destacado o processo de expansão das Instituições de Ensino Superior privadas como campo aberto de atuação para o bacharel.

Pesquisando sobre a expansão das instituições privadas por meio do documento de 2006, lançado pelo Instituto Nacional de Estudos e Pesquisas (INEP), com o título "Educação Superior Brasileira 2001-2004", percebi que o marco legal desse processo de expansão foi a LDB atual, no 9.394/96, que desencadeia um amplo processo de reformulação no Sistema de Educação Superior no Brasil.

Isso abre a possibilidade de crescimento de aproximadamente $120 \%$ de instituições, principalmente de instituições privadas. Beneficiadas pelas novas condições legais estabelecidas pela Lei no 9.870 de 23 de novembro de 1999, que possibilitam a criação das Instituições de Ensino Superior (IES) - com fins lucrativos, essas IES passaram de 711 em 1996 para 1.789 em 2004, um aumento de $151,6 \%$ na rede privada de Ensino Superior.

Todavia, no censo do INEP de 2008, no estado, existem vinte e três IES, sendo cinco públicas, e dezoito particulares, contado muitas destas com a contribuição de professores das universidades públicas, em especial, muitos de nossos entrevistados que contribuíram como consultores para a criação de cursos e chegaram a lecionar nessas instituições.

Atualmente, essas instituições privadas ganham força por meio de convênios de concessão de bolsas de estudo para estudantes de baixa renda junto ao Governo Federal ampliando esse número em relação a 2008, e ainda, com a política de expansão das Universidades Federais, por meio do Plano de Reestruturação e Expansão das Universidades Federais (REUNI), e também com a ampliação dos números de Institutos com as expansão dos Institutos Federais de Educação, Ciência e Tecnologia do Rio Grande do Norte (IFRN). Essas ações se constituem como parte de um conjunto mais amplo de medidas inseridas no Plano de Desenvolvimento da Educação (PDE), sendo instituído como reconhecimento do papel estratégico das universidades, em especial do setor público para o desenvolvimento econômico 
social. Essas medidas conduzem à configuração da "universidade nova", ou seja, visam uma reordenação do papel da educação superior, em andamento no Brasil.

O REUNI, instituído pelo Decreto $n^{\circ}$ 6.096, de 24 de abril de 2007, constitui-se como uma proposta de mudança na qual o Governo Federal passou a adotar uma série de medidas a fim de retomar o crescimento do ensino público, criando um programa multidimensional e, ao mesmo tempo, acadêmico, político e estratégico. Essa expansão teve início em 2003, ainda no primeiro mandato do Presidente Luiz Inácio Lula da Silva, e o REUNI constitui a segunda etapa desse programa de expansão prevista para ser concluída em 2012, representando para a reestruturação acadêmica uma inovação que, de acordo com o discurso do Governo Federal, "[...] significará, em curto prazo, uma verdadeira revolução na educação superior pública do país" (MEC, 2008, s/n).

Sobre essas expansões das IES, Pimenta e Anastasiou (2005, p. 128) relatam que "[...] no caso dos professores de educação superior, as oportunidades de emprego vêm aumentando, com a expansão das instituições particulares de ensino, em todo o território Nacional." Esse contexto tem criado oportunidades para que profissionais bacharéis optem pela docência universitária como uma possibilidade de aumento da renda, de empregabilidade, considerando ser o ensino privado uma porta aberta para esses profissionais.

No comentário de Cunha, Brito e Cicillini (2006) sobre como parece fácil tornar-se professor universitário no Brasil, é afirmado:

\footnotetext{
Dormi aluno (a) e acordei professor (a), é a frase, que de certa forma resume a situação do despreparo que os professores que atuam nas áreas investigadas vivenciam na sua trajetória profissional. A interface de dormir e acordar representa também as possibilidades de diálogos que podem/devem ser tecidas no fazer-se professor (CUNHA; BRITO e CICILLINI, 2006, p. 216).
}

Esse comentário me leva a perceber, no caso das universidades privadas, o problema da exigência sobre a formação do bacharel para ingressar no Ensino Superior ser mínima, pois, devido à expansão citada, existiu uma ampla possibilidade de atuação desses profissionais nos processos de aberturas de cursos e consequentemente de um grande número de profissionais que pudessem atuar como docentes nessas instituições.

As regras de ingresso de profissionais para o Ensino Superior não se constituem de forma rigorosa. De acordo com o que contam muitos dos professores entrevistados, muitos foram convidados ou tiveram fácil acesso a rede privada de Ensino Superior, especialmente em períodos de criação de cursos, mesmo aqueles que não tinham experiências com a docência.

Partindo então dessa pouca exigência de formação, quem tinha cursos de mestrado e doutorado tornou-se requisitado, e quem desejava ingressar na carreira docente nas Instituições Federais passou a se preocupar em entrar para a Pós-graduação. Ter especialização em algumas áreas, na época, já era uma diferenciação; quem obtinha os títulos de mestrado ou doutorado, ainda mais reconhecimento tinha, seja como professor substituto nas instituições federais, seja com professor contratado, nas universidades e faculdades privadas, como explica Luiz (2011): “[...] não era muito fácil você encontrar alguém com mestrado em economia, especialização já era pouco ofertada, devido à falta de Pós-Graduação na área."

Nessa perspectiva, explicitamos as influências da Pós-graduação nas trajetórias para a docência universitária, embora ressalte novamente que, mesmo separando esses caminhos, as trajetórias de trabalho continuam influenciando, pois muitos chegam à Pós-graduação inicialmente como uma forma de se qualificarem profissionalmente e atuarem na área de formação inicial. 
As trajetórias docentes movem-se para além dos limites do desejo idealista, ou ingênuo, pois elas se constroem a partir de tensões, de processos dilemáticos (ELIAS, 1998), que são estabelecidos entre o desenvolvimento profissional que esperamos e os fatores externos como o mundo do trabalho, a ampliação do ensino privado, as políticas governamentais, o aumento das necessidades produtivas, da carga horária de trabalho, dos baixos salários, das necessidades de qualificação profissional, dentre outros aspectos que demarcam as mudanças sociais

\section{AS INFLUÊNCIAS DA PÓS-GRADUAÇÃO NA FORMAÇÃO DO BACHAREL DOCENTE}

Percebo como marco de influência nos percursos acadêmicos de muitos bacharéis que atuam como professores a inserção nos programas de Pós-graduação, seja no âmbito lato sensu, seja no stricto sensu. Com a realização da pesquisa confirmei que a Pós-graduação significa um espaço de qualificação profissional e de busca para o ensino universitário, como afirma, por exemplo, Luiz (2011): "[...] entrei para o mestrado porque acreditava que, melhorando minha qualificação, poderia ser melhor como profissional."

A Pós-graduação como educação continuada pode ser considerada atualmente como uma expressão de ordem quando relacionada ao mundo do trabalho, pois permite que o profissional possa competir com um "diferencial”, já que o mercado de trabalho está cada vez mais exigente, solicitando cada vez mais qualificação. Essa qualidade profissional é interpretada como a obtenção de cursos, títulos e maior graduação, ou seja, quanto maior o número de cursos e graduação nos currículos dos candidatos, mais qualificados eles são considerados.

Diante da recente história de um sistema de Pós-graduação no Brasil, entre os anos de 1965 e 1970, pode-se considerar que ela surge como uma necessidade de criação de quadros especializados e qualificados para o modelo de desenvolvimento econômico-social desse contexto, como afirma Sguissardi (2000, p. 57): “[...] os novos tempos exigiriam uma estrutura específica de Pós-graduação que garantisse essa qualificação em nível e escala muito maiores e comportasse formas mais simples e eficientes de avaliação e controle."

Bianchetti e Machado (2006), explicam ainda que, antes que no nosso país existissem sistematizados os cursos de Pós-Graduação, especialmente stricto sensu, a titulação de mestres e doutores, via de regra, tinha que envolver profissionais ou mesmo instituições estrangeiras que pudessem formar um novo quadro de profissionais. O que se pode ter claro é que a primeira geração que obteve esses títulos foi formada por professores universitários que a buscavam nas universidades estrangeiras.

Considerando a Pós-graduação no Brasil como uma possibilidade de formação recente, na Universidade Federal do Rio Grande do Norte ela começa na década de 1970. No Centro de Ciências Sociais Aplicadas, os cursos de Pós-graduação mais antigos são os programas em Educação e Administração, sendo criado posteriormente o de Direito, criado em 1996 com a implementação do mestrado interinstitucional em convênio com a UFPB e em 1999, foi aprovado no CONSEPE o curso de Mestrado na UFRN.

Ainda na década de 1990 é criado o Programa de Pós-graduação em Economia, oferecendo cursos de especialização lato sensu, todavia o curso de Mestrado só teve inicio em 2002. Na década seguinte, são criados os programas de Serviço Social, Ciências Contábeis e Turismo. O Programa de Biblioteconomia, mais recente, ainda não consolidou a implementação da oferta de cursos stricto sensu.

Atualmente a UFRN, por meio da Pró-Reitoria de Pós-Graduação, visa a formação de docentes, pesquisadores e profissionais de alto nível, conforme descrito em sua página oficial no 
site institucional. Conta atualmente com quarenta e três cursos de Mestrado, vinte e quatro cursos de Doutorado, cerca de sessenta cursos de Especialização e vinte e um programas de residência médica, o que tem causado um forte impacto na formação de profissionais para atuação em Ciência e Tecnologia no nosso Estado.

Diante desse cenário de uma Pós-graduação recente na UFRN, muitos dos professores entrevistados tiveram que fazer os cursos de Mestrado ou Doutorado em universidades fora do Rio Grande do Norte, principalmente pela maioria dos cursos terem sido criados nos últimos dez anos: "[...] em toda a história do Rio Grande do Norte, sou o décimo mestre em Direito [...]" explica Henrique (2011), que após concluir o curso de Direito, sentia-se realizado com a profissão: "[...] facilmente me apaixonei pela pesquisa na área, então o caminho natural foi seguir para o mestrado e na época não tinha aqui."

Diante da falta de oportunidades no RN de fazer uma Pós-graduação em Direito stricto sensu, Henrique conta: "[...] fui pra Pernambuco fazer mestrado e logo no retorno fiz o projeto de doutorado e o curso, pela vocação pela pesquisa, e não necessariamente pelo ensino."

Ao explicar sua trajetória, Henrique (2011), afirma que desde que foi monitor não deixou de ensinar, mas que o que para ele tem vocação, é pela pesquisa, explica ainda que, para se manter no mestrado em Pernambuco: "[...] tive que ser professor substituto na UFPE, pois pedi rescisão do meu contrato de trabalho pra estudar." Mesmo retornando para o Rio Grande do Norte, o professor explica que também trabalhou como professor substituto, pois "[...] deixou de ser analista judiciário para terminar o doutorado, mas isso me deixou angustiado."

Malagris et al. (2009) explica que dentre os fatores externos que mais causam estresse e ansiedades nos estudantes de Pós-graduação, destaca-se o fato de que muitos não têm condições de se manterem como estudantes fora do mundo do trabalho. Isso pode ser percebido na fala de Luiz (2011): "[...] não tinha como deixar de trabalhar para estudar, então a forma que encontrei de ter um horário de trabalho mais flexível foi sendo professor universitário."

Sophia (2011), por sua vez, explica que a docência surge para o graduado em Turismo como uma saída profissional já que "[...] não existe campo para o bacharel do turismo." Por isso "[...] os alunos, mau se formam e já falam em fazer Pós-graduação para serem professores [...]", explica a professora, pois para os alunos "[...] ser professor do curso de Turismo é uma forma de ter sucesso na profissão." Para Sophia, o grande número de professores substitutos que passaram pelo curso, contribuiu muito com a formação da ideia de que ser professor universitário significa ter sucesso profissional, considerando a realidade de desemprego ou formas de empregos em que estavam inseridos os bacharéis do turismo em Natal egressos do curso.

Essa também foi a forma encontrada pela professora de sentir-se realizada profissionalmente: "[...] assim que conclui o mestrado, comecei a fazer concurso pra professora [...]", pois, assim como já havia ministrado aulas particulares, ao fazer o curso de guia turístico, Sophia é contratada pelo SENAC como professora desse curso técnico: " [...] como estava com a formação no curso de turismo, e detinha o curso de guia turístico, pela minha experiência consegui dar aulas no SENAC."

A docência passa então, para essa professora, a se consolidar como profissão segura no sentido empregatício, pois durante seu percurso de formação e profissional, essa foi a área que mais esteve aberta a ela para trabalho. Considerando isso, ela explica que: "[...]não tinha como não pensar em ser professora, entrei para o mestrado com o objetivo de ensinar na universidade." Sophia (2011), assim como Luiz, passa pelo curso no nível de Pós-graduação trabalhando, pois nenhum deles recebeu bolsa de estudos. 
Assim como esses dois professores, Laura (2011) também busca a Pós-Graduação, pois explica que, depois da experiência como professora colaboradora, buscou fazer mestrado para se qualificar melhor profissionalmente. Apesar de continuar como servidora pública federal na área do direito, desejava ainda atuar no ensino: "[...] cheguei a ser aprovada no mestrado, a cursar algumas disciplinas, mas não deu pra conciliar o trabalho com os estudos, tive que abandonar o mestrado." Por isso, apesar de voltar a fazer concurso para efetivo, alguns anos depois, Laura sente-se mau por não ter conseguido terminar o mestrado: “[...] eu gosto de ensinar, queria muito ter concluído, sei que isso é importante na carreira acadêmica, mas é muito cansativo, não consigo."

Ainda segundo Malagris et al. (2009), ao realizar o estudo sobre o nível de estresse em alunos de Pós-graduação na Universidade Federal do Rio de Janeiro, a alta competitividade do mundo do trabalho, a necessidade de cumprimento de prazos, a sobrecarga de atividades, as necessidades de se manter empregado, as ansiedades quanto ao futuro profissional e as situações em que são avaliados, são os grandes motivadores de estresse dos alunos que estão inseridos nesse contexto, e muitas vezes são os motivadores dos índices de abandono, ou jubilamento dos alunos de Pós-graduação.

Assim como Laura (2011), que buscou se qualificar na Pós-graduação no nível de mestrado para melhor atuar como professora, Alexandre (2011), também mesmo como efetivo na UFRN, não conseguiu concluir o curso em um primeiro momento: "[...] comecei a fazer mestrado fora, minha família ficou aqui, então por motivos particulares, tive que abandonar o curso." Apesar de hoje ser mestre em Serviço Social, apenas posteriormente e com o mestrado instituído em Natal, ele consegue concluir o curso.

Considerando as dificuldades apresentadas por esses professores nos percursos da Pósgraduação, embora eles reconheçam a importância do curso para sua qualificação na docência universitária, parto da compreensão de que é necessário uma reflexão mais ampla sobre a necessidade de se implementar meios de auxiliar os alunos de Pós-graduação que não podem deixar o trabalho para estudar. Esse é um fato presente nas condições socioeconômicas em que muitos deles se inserem, do contrário, os cursos de Pós-Graduação ficarão limitados àqueles que têm condições de manterem-se sem trabalhar ao longo de dois ou três anos de estudos.

Sobre isto Malagris et al. (2009), em seus estudos analisa que existe a ausência de políticas internas de assistência estudantil que reconfigurem as estruturas de ensino na Pósgraduação. Para ela isto faz com que não haja como pensar em diminuições dos níveis de depressão, problemas de saúde, ansiedade aguda, hipertensão arterial, abuso de substâncias químicas, dentre outros casos presentes nos alunos por ela pesquisados, sejam superados.

Outra professora influenciada pela Pós-Graduação foi Raquel (2011). A despeito de que no seu percurso profissional as oportunidades de trabalho estavam abertas, o desejo de ser pesquisadora, mudou sua trajetória profissional, pois depois de trabalhar no SEBRAE como consultora empresarial, e depois no governo de Sergipe, ela explica que "enquanto estava no governo, criamos um Núcleo de Tecnologia, me voltei pra academia e vi a necessidade de me requalificar."

Nesse sentido de melhorar sua qualificação para voltar a trabalhar com empresas, pois “[...] só executava por anos, quis voltar a estudar, então a alternativa que encontrei foi fazer mestrado na área empresarial." Logo que conclui o mestrado, volta para o SEBRAE, e como queria fazer o doutorado, Raquel (2011) explica que começou a ficar inviável trabalhar no local: "[...] lá você é um técnico que vai para empresas e tem que ter soluções prontas, eu não tinha tempo pra estudar." 
Diante da situação que o SEBRAE colocava para os funcionários de muita exigência no atendimento às empresas, Raquel (2011) expressa como se sentiu mal, já que o mestrado tinha desenvolvido nela grande interesse pela pesquisa: "[...] não tinha ambiente mais pra mim, decidi voltar para a academia, então uma amiga falou do concurso da universidade de forma casual."

O contexto do desejo de voltar a estudar, de cursar o doutorado e não se adaptar ao ambiente do trabalho mudou sua trajetória como consultora de empresas: "[...] eu não vim procurar a docência. Vim ver como era e deu certo, pois era um espaço onde eu poderia continuar a estudar trabalhando."

Para Henrique e Raquel, então, ser professor universitário se consolida no processo de formação no nível de Pós-Graduação, no qual o interesse primeiro foi a pesquisa e não a docência, esta tem sido uma forma de observar as motivações do grande contingente de bacharéis que atuam como docentes, na medida em que a profissão passa a se configurar como escape para que deseja ser pesquisador.

\section{CONSIDERAÇÕS FINAIS}

No decorrer deste texto, os professores percebem a importância da Pós-graduação para a docência universitária, todavia, alguns passaram por dificuldades diante do contexto de terem que estudar e trabalhar ao mesmo tempo, principalmente em um processo onde os Programas de Pós-graduação ainda não estavam consolidados.

Para alguns a docência surge, devido ao sucesso nas profissões que desempenhavam, para outros, devido à necessidade de emprego, entretanto, muitos buscam por motivos inesperados, diante da necessidade de melhorar da saúde, de se desenvolver vencendo a timidez, para se legalizar na instituição. Todas as motivações expostas e trajetórias rumo à docência universitária deixam claro que ser professor não era objeto de desejo dos profissionais, mas que surgiu diante de uma circunstância de vida com necessidades diversificadas, embora influenciadas pelo desejo de desenvolver na pesquisa e na ampliação de estudos.

Consideramos a partir do exposto que existe a necessidade do estreitamento dos vínculos entre os Programas de Pós-graduação e a graduação, na medida em que os alunos de mestrado e doutorado, em especial, no decorrer de sua formação como pesquisador, garanta a formação como docente de nível superior, objetivo primeiro desses cursos conforme a Coordenação de Aperfeiçoamento de Pessoal de Nível Superior (CAPES).

Certamente, a experiência de alunos de pós-graduação na atividade docente, por meio de estágios e do fortalecimento das disciplinas voltadas para a formação de professores nos currículos obrigatórios desses cursos, poderia proporcionar a formação para a docência universitária de um maior contingente de mestres e doutores a serem preparados para enfrentar as incertezas e as urgências que são próprias do contexto educacional.

\section{REFERÊNCIAS}

ALEXANDRE (2011). Entrevista. Entrevistado por OLIVEIRA, V.S. Natal, fevereiro. AUGÉ, M. (1999). O sentido dos outros: atualidade da antropologia. Petrópolis, RJ: Vozes. BIANCHETTI, L., \& MACHADO, A. M. (Orgs.). (2006). A bússola do escrever: desafios e estratégias na orientação de teses e dissertações. São Paulo: Cortez.

CUNHA, A. M. O., BRITO, T. A. R., \& CICILLINI, G. A. (2006). Dormir aluno (a) acordei professor: Interfaces da formação para o exercício do ensino superior. In: SILVA, J.R.; O.LIVEIRA, J. F., \& MANCEBO, D. (Orgs.). Reforma Universitária: Dimensões e perspectivas. São Paulo: Alínea e 


\section{Átomo.}

Decreto no 6.096, de 24 de abril de 2007. Institui o Programa de Apoio a Planos de Reestruturação e Expansão das Universidades Federais- REUNI. Recuperado de http://www.planalto.gov.br/ccivil 03/ ato2007-2010/2007/decreto/d6096.htm.

ELIAS, N. (1998). Envolvimento e Alienação. Rio de Janeiro. Bertrand Brasil.

GARCÍA, C. M. (1999). Formação de Professores: para uma mudança educativa. Porto: Porto Editora.

HENRIQUE. (2011). Entrevista. Entrevistado por OLIVEIRA, V.S. Natal, Janeiro.

HOUSSAYE, J. (Org.). (2004). Manifesto a favor dos Pedagogos. Porto Alegre: Artmed.

INEP. (2006). Educação Superior Brasileira 2001-2004 -. Brasília: Instituto Nacional de Estudos e Pesquisas Educacionais Anísio Teixeira.

KAUFMANN, Jean-Claude. L'entretetien compréheusif. Paris: Nathan, 1996.

LAURA. Entrevista. (2011). Entrevistado por OLIVEIRA, V.S. Natal, Janeiro. Lei no 9.394, de 20 de dezembro de 1996. Estabelece as diretrizes e bases da educação nacional. Recuperado de http://www.planalto.gov.br/ccivil_03/leis/L9394.htm Lei no 9.870 de 23 de novembro de 1999. Dispõe sobre o valor total das anuidades escolares e dá outras providências. Recuperado de http://www.planalto.gov.br/ccivil 03/leis/L9870.htm

LUIZ. Entrevista. (2011) Entrevistado por OLIVEIRA, V.S. Natal, Janeiro.

MALAGRIS L. E. N.; SUASSUNA, A. T. R., \& BEZERRA, D. V . (2009, Abril). Níveis de estresse e características sociobiográficas de alunos de pós-graduação. Psicologia em Revista, Belo Horizonte, v. 15, n. 1, p. 184-203.

MEC. (2008). REUNI 2008: Relatório do primeiro ano. Brasília: MEC/ SEsu/ DIFES. NÓVOA, António (Org.). (1995). Profissão professor. Porto: Porto editora.

PIMENTA, S. G., \& ANASTASIOU, L. G. C. (2005). Docência no ensino superior. São Paulo: Cortez.

PIMENTA, Selma Garrido (Org.) (2007). Saberes pedagógicos e atividade docente. São Paulo: Cortez.

RAQUEL. Entrevista.(2011). Entrevistado por OLIVEIRA, V.S . Natal, Janeiro.

SGUISSARDI, Valdemar (Org.). (2000). Educação superior:Velhos e novos desafios. São Paulo: Xamã.

SILVA, R. F. (2006). Compreender a "entrevista compreensiva". Revista Educação em Questão, Natal, v. 26, n 12, p. 31- 50.

SOPHIA. Entrevista. (2011). Entrevistado por OLIVEIRA, V.S. Natal, Janeiro. 